\title{
A abordagem da educação sexual nos espaços escolares: um olhar sobre a perspectiva dos alunos do ensino médio de Guaraí/TO
}

O presente artigo é resultado da percepção dos alunos acerca do tema "educação sexual dentro do ambiente escolar", no qual se buscou examinar as influências externas, a vergonha em transmitir o assunto para os discentes e a falta de pessoas capacitadas na área da educação sexual. Nesse sentido, foi aplicado um questionário semiestruturado de questões abertas e fechadas, com alternativas de múltiplas escolhas, buscando-se observar os desafios enfrentados pelos professores e alunos em abordar o tema, suas metodologias de ensino e aprendizagem, os possíveis fatores sociais que possam interferir no processo de aprendizagem e sua importância dentro do ambiente escolar. Com este trabalho, pode-se analisar a grande relevância de se trabalhar este tema, para que possam formar jovens mais conscientes de suas atitudes, entre outros fatores que podem ser de grande importância na vida social do discente. Esta pesquisa mostrou escassez de material didático, a necessidade de aulas dinamizadas e de palestras sobre o assunto. Esta investigação contribui para solucionar os desafios existentes e analisar as possíveis influências sociais, mostrando a importância da participação e acompanhamento dos pais no processo de ensino, assim como propor novas metodologias de ensino.

Palavras-chave: Ensino Sexual; Ambiente escolar; Fatores Sociais.

\section{The approach of sexual education in school spaces: a look at the perspective of students of the middle school of Guaraí/TO}

This article is a result of the students' perceptions about the theme of "sexual education within the school environment", which sought to examine external influences, the shame in transmitting the subject to the students and the lack of trained people in the area of sex education. In this sense, a semi-structured questionnaire of open and closed questions was applied, with alternatives of multiple choices, seeking to observe the challenges faced by teachers and students in addressing the theme, their teaching and learning methodologies, possible social factors that may interfere in the learning process and its importance within the school environment. With this work, one can analyze the great relevance of working on this topic, so that they can train young people more aware of their attitudes, among other factors that may be of great importance in the social life of the student. This research showed a shortage of didactic material, the need for dynamic classes and lectures on the subject. This research contributes to solve the existing challenges and to analyze the possible social influences, showing the importance of the participation and accompaniment of the parents in the teaching process, as well as to propose new teaching methodologies.

Keywords: Sexual Education; School Environment; Social Factors.

Topic: Práticas, Didática e Metodologias de Ensino

Reviewed anonymously in the process of blind peer.

Joab Cardoso Guedes

Faculdade Guaraí, Brasil

http://lattes.cnpq.br/6447173238092945

joabcardoso1@outlook.com

Hérica Oliveira Santos

Faculdade Guaraí, Brasil

http://lattes.cnpq.br/9456571239122408

herica160716@gmail.com

Izidorio Paz Fernandes Neto

Faculdade Guaraí, Brasil

http://lattes.cnpq.br/7911321052215737

izidorio.paz@hotmail.com
Received: 18/12/2017

Approved: 27/12/2017
Referencing this:

GUEDES, J. C.; NETO, I. P. F.; SANTOS, H. O.. A abordagem da educação sexual nos espaços escolares: um olhar sobre a perspectiva dos alunos do ensino médio de Guaraí/TO. Educationis, v.5, n.2, p.34-40, 2017. DOI: http://doi.org/10.6008/SPC2318-3047.2017.002.0004 


\section{INTRODUÇÃO}

A educação sexual é um tema complexo e ainda não desvendado. Por outro lado, faz-se presente em escolas nos temas transversais proposto nos PCNs (Parâmetros Curriculares Nacionais do Ministério da Educação), mostrado nas multimídias e cercado por inquietações e dúvidas nos próprios adolescentes. Neste sentido, os planos curriculares nacionais corroboram que o papel da escola é proporcionar um espaço de discussão e reflexão que irá auxiliar no processo de formação do indivíduo, sendo esta diferenciada da educação realizada pela família (BRASIL, 2001).

A educação sexual é uma preparação e orientação aos adolescentes e jovens para que venham ter uma relação sexual saudável por meio da prevenção de doenças sexualmente transmissíveis, gravidez indesejada, conhecendo o seu corpo e reconhecendo as mudanças de gênero e orientação sexual nas relações sociais (QUIRINO et al., 2012). Nesse ponto de vista, a educação sexual deve posicionar os docentes com as competências necessárias para repassar este conhecimento para os discentes no ambiente escolar, ajudando-os a removerem suas incertezas, impaciências e apreensões. O termo "educação sexual" não consiste em meramente repassar noções acerca do sexo, mas dos relacionamentos, transmissão de valores, atitudes e comportamentos (SAMPAIO,2005).

Através do dispositivo pedagógico, nesse contexto, qualquer lugar em que o indivíduo aprende ou modifica as relações consigo e com outros, constitui-se da experiência do sujeito e se entrecruzam os discursos que definem o ser (LARROSA, 1994). Através da análise do currículo escolar, as diversas estratégias de poder medeiam a criação do sujeito pensante. De acordo com Altmann (2001) a escola é uma entre as múltiplas instâncias sociais que exercitam uma pedagogia da sexualidade e do gênero por meio das várias tecnologias governamentais. Louro (1999) afirma que tais processos são contínuos e completados através de autodisciplinamento e autogoverno exercidas pelos sujeitos sobre si próprios, havendo um investimento exagerado e produtivo desses sujeitos na determinação de suas formas de ser ou existir sua sexualidade e seu gênero.

No contexto escolar, não existe uma obrigatoriedade em falar de educação sexual, pois há uma inexistência de lei, mas existem os PCNs que instituíram a orientação sexual como um tema transversal (ALTMANN, 2001). O presente artigo tem o intuito de analisar a percepção da educação sexual dentro do ambiente escolar por parte dos docentes e discentes, bem como os fatores externos que influencia neste processo de ensino e aprendizagem.

\section{METODOLOGIA}

Esta pesquisa possui um caráter qualitativo. Participaram da presente exploração, alunos da rede pública estadual de ensino médio das turmas do 1으 ano e professores das mesmas escolas em que foi pesquisado. Para essa coleta de dados foi empregado um questionário contendo 10 questões de forma semiestruturado, 8 perguntas com alternativas de múltiplas escolhas e 2 abertas com respostas pessoais, aplicados a todos os alunos presentes na sala de aula e de forma aleatória. 
Os questionários continham perguntas relacionadas ao tema educação sexual, que visavam analisar os principais temas abordados, possíveis influências sociais e culturais por parte dos discentes, possível interferência de sua família no processo de aprendizagem, e avaliar seus respectivos professores atuantes da disciplina. A análise do questionário foi feita a partir da estatística descritiva segundo a metodologia de Reis et al. (2002) que tem por objetivo averiguar um grupo de pessoas relatando aspectos relevantes.

\section{RESULTADOS E DISCUSSÃO}

Foram obtidos 211 questionários respondidos pelos alunos, sendo, entre eles 109 do sexo masculino e 102 femininos. Entre o sexo masculino a faixa etária de idade foi de 14 a 19 anos e no feminino entre 14 a 20 anos. Conforme consta na figura 1, segundo os alunos, a falta de capacitação dos professores na área seria o maior desafio (34\%) mostrando a necessidade de se investir na capacitação docente.

Outro fator a ser enfrentado é a falta de material didático (30\%), dificultando a qualidade do ensino sexual. 21\% dos alunos não consideram ao assunto relevante, o que compromete com o ensino de educação sexual e $13 \%$ sofre influência da família, mudando todos os conceitos ensinados na escola. No que se o se trata a sexualidade, Gomes (2013) diz que não é uma idealização direta, e sim cruzado pelas condições históricas, sociais e culturais. Já para Lionço et al. (2008) é algo isolado, privado e biológico, não sendo de construção sociocultural, resultando de práticas limitadas.

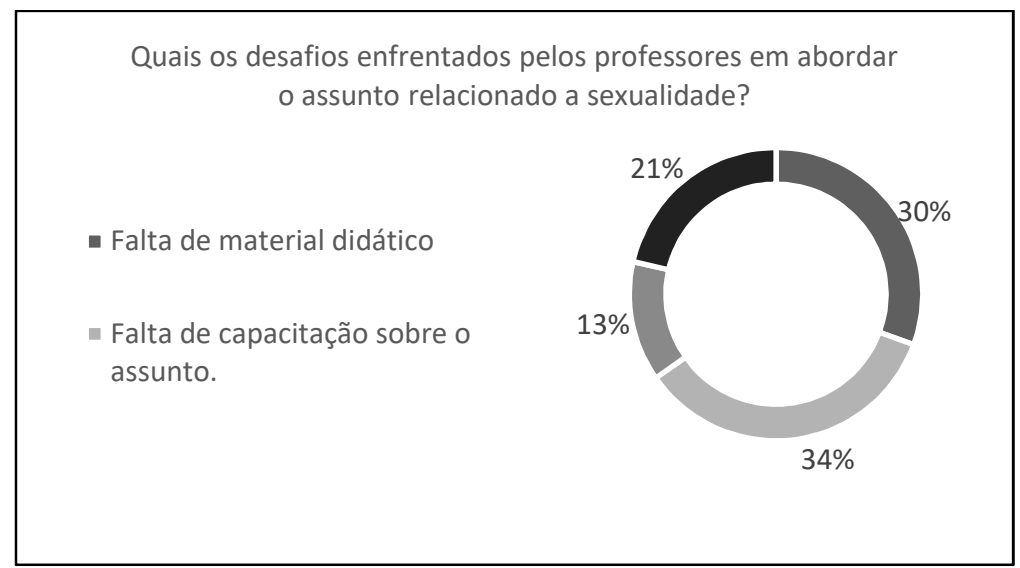

Figura 1: Desafios enfrentados pelos professores no ensino de educação sexual.

De acordo com os planos curriculares nacionais (BRASIL, 2001), para a formação do indivíduo é necessário que haja um espaço de discussão e reflexão, no qual isso cabe a escola proporcionar esse espaço. A família tem o papel crucial para a formação social do indivíduo, assumindo responsabilidades, sendo o primeiro contato com informação, não podendo deixar que se tenha educação somente nas escolas (GASPAR et al, 2006).

Para aqueles que possuem o desejo de aprender de forma significativa, um ambiente dinamizado propicia uma aprendizagem intensificada (BELMONT et al., 2008). A interação entre sujeito e objeto dentro do ambiente escolar ocasiona uma relação de conhecimento, e não é de necessidade ser somente a conexão entre aluno e professo (XAVIER et al., 2008). 
A absorção de forma significativa do conteúdo, para os alunos, dá-se por aulas dinamizadas (34\%) saindo da rotina de aulas tradicionais, juntamente com ministração de palestras (31\%) e videoaulas (26\%) relacionados ao assunto, conforme apresentado na figura 2. Ainda foi observado que a leitura (6\%) é de pouca significância, pois se relaciona ao tradicionalismo.

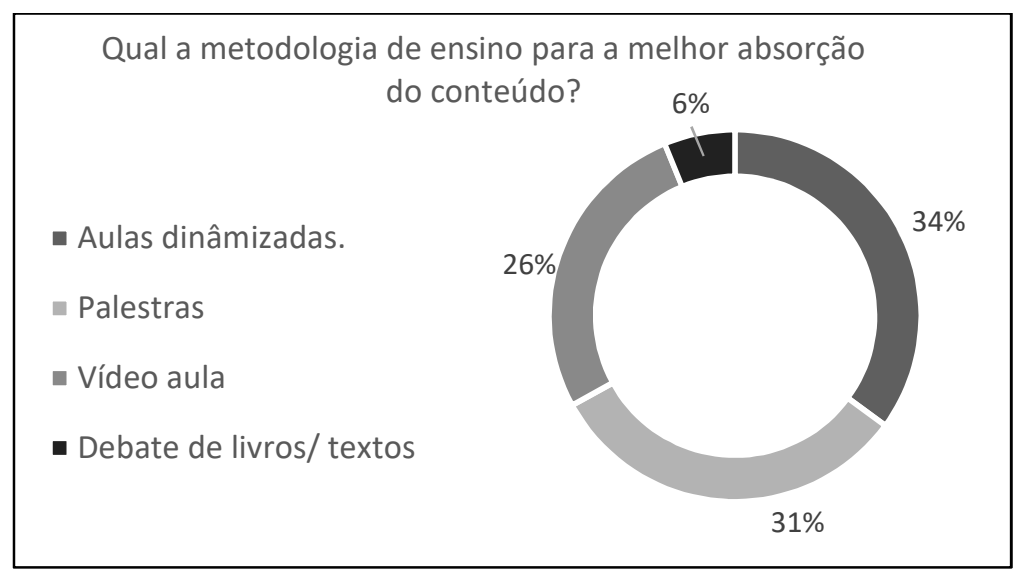

Figura 2: Metodologias de ensino aplicados por professores.

De acordo com Bomfim (2009), a construção de novos valores, percebida na mudança do tempo, trouxe modificações sociais como liberdade sexual e a reprodução humana. Esstando com um novo olhar conduz a importância de abordar esses assuntos na sala de aula. 38\% dos alunos afirmaram que a orientação sexual é um eixo norteador na educação sexual mostrando a necessidade de abordar essa temática, assim minimizando o preconceito existente no meio social. $29 \%$ dos entrevistados relataram que o início da vida sexual é importante na educação sexual, tendo como necessidade de se trabalhar o assunto para prevenção de doenças e uma vida sexual saudável seguida de 19\% gravidez na adolescência, e 13\% DST's.

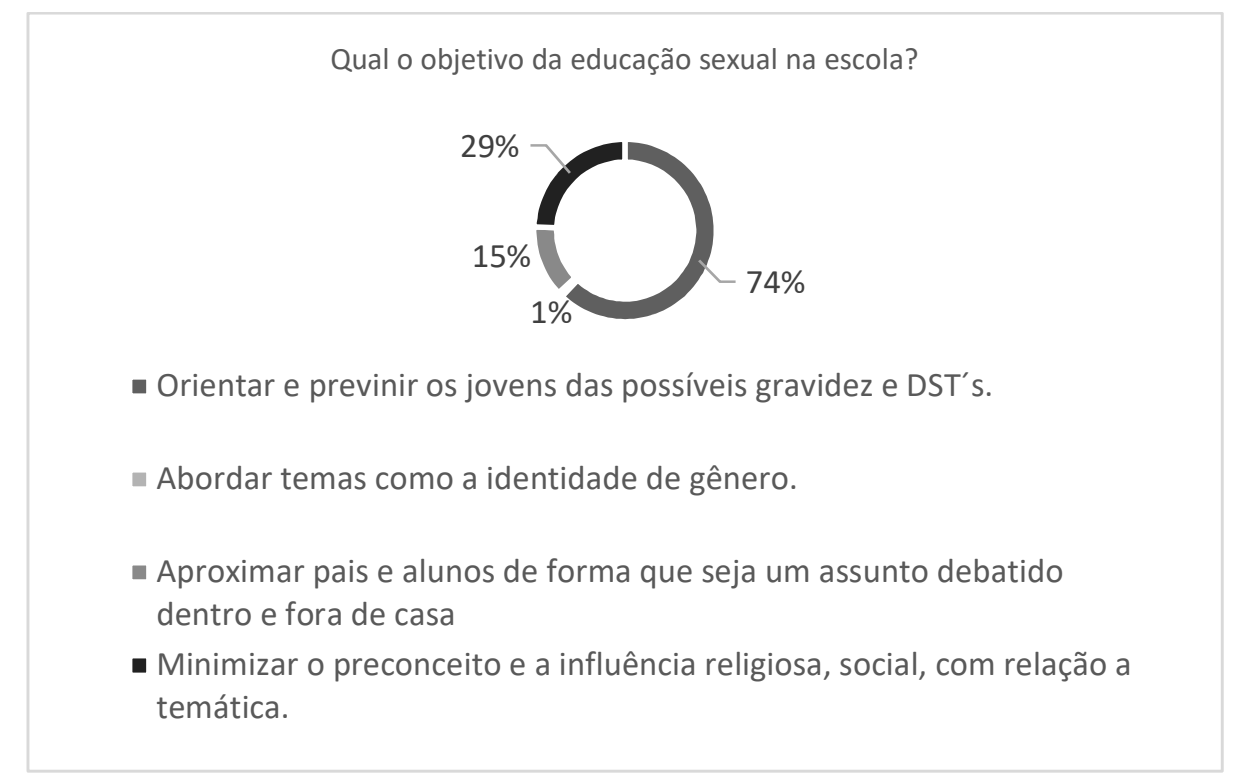

Figura 3: Objetivo da educação sexual.

Com o início precoce da atividade sexual dos adolescentes traz consigo curiosidades, onde eles não possuem conhecimento passando por condições de constrangimento como a gravidez indesejada e doenças 
sexualmente transmissíveis Taquette et al. (2004) e Silva et al. (2011). A orientação e prevenção de jovens das possíveis gravidez e DST's seria o objetivo de se educar sexualmente (74\%), contribuindo para amenizar dois fatores que afetam os jovens. Um dos alunos incluiu como alternativa que ensinar a fazer sexo seria o objetivo da educação sexual mostrando a falta de entendimento a respeito da abrangência e significado em relação ao tema. $29 \%$ ressaltaram o preconceito e a influência religiosa e social na temática, $15 \%$ aproximar os pais e alunos para debater o assunto nos diversos ambientes e apenas $1 \%$ identidade de gênero, conforme explicitado na figura 3.

A mudança do comportamento social, principalmente da sexualidade, tem contribuído para o alto índice de gravidez na adolescência, indicando a relevância da educação referente a temática (SANTOS,2006). A puberdade e amadurecimento direciona a prática sexual e os riscos existentes na relação desprotegida, havendo necessidade de orientação (FIGUEIREDO, 2002).

Segundo os alunos, a educação sexual poderia minimizar os índices de DSTs e gravidez na adolescência (78\%). Com o conhecimento, mudariam suas formas de agir, trazendo uma conscientização. Muitos afirmaram que existe uma falta de diálogo a respeito do tema, também partes dos questionados disseram que não (9\%), pois os adolescentes sabem dos riscos mesmo sendo educados.

A maior parte dos alunos disseram que a família não interfere no processo de ensino e aprendizagem (62\%), permanecendo neutra a esse assunto. Boa parte não soube explicar o porquê da resposta negativa. Os que responderam sim (28\%), disseram que não há boa relação com os pais, pois não gostam que falem sobre o assunto. Em relação à educação sexual, Gaspar et al. (2006) afirma que deve ter envolvimento da família no processo de ensino relacionado a sexualidade, mas que seja de forma saudável, sem que exista preconceito ou até mesmo medo de abordar o assunto, buscando sempre vencer os tabus existentes. Dos entrevistados, $72 \%$ dos discentes possuem vergonha de falar sobre o tema no ambiente escolar, bem como o desconhecimento a respeito do tema (14\%), preconceito (8\%) e por motivos religiosos (5\%).

No ambiente escolar, para Beraldo (2003), abordar educação sexual propicia vastas polêmicas, estas sendo inconvenientes e desnecessárias, mostrando que ainda falar sobre o assunto é um grande tabu. Ao relacionar a família, os pais não se sentem confortáveis em discutir com seus filhos, deixando de repassar orientações corretas. Contrapondo, Salomão et al. (2013) os pais estão se preocupando mais com os filhos, mudando a forma de falar sobre sexualidade se tornando mais visível a discussão e tendo mais interesse do diálogo com os filhos. Uma grande parcela dos alunos indicou que a própria educação dificulta o ensino (40\%), a família não participa do processo de educação (24\%), a cultura $(20 \%)$ e a igreja (14\%) também interferem no processo de educação escolar (figura 4).

Moises et al. (2010) afirma que a escola deve promover uma educação integral incluindo a educação sexual, de forma que venha provocar questionamentos e mudar visões destorcidas. A orientação sexual abordando conceitos como homossexualidade, bissexualidade, transexualidade, foi apontada como o mais complexo de se trabalhar pelo professor (41\%), gravidez na adolescência (34\%), início da vida sexual (29\%) e DST's (13\%). 


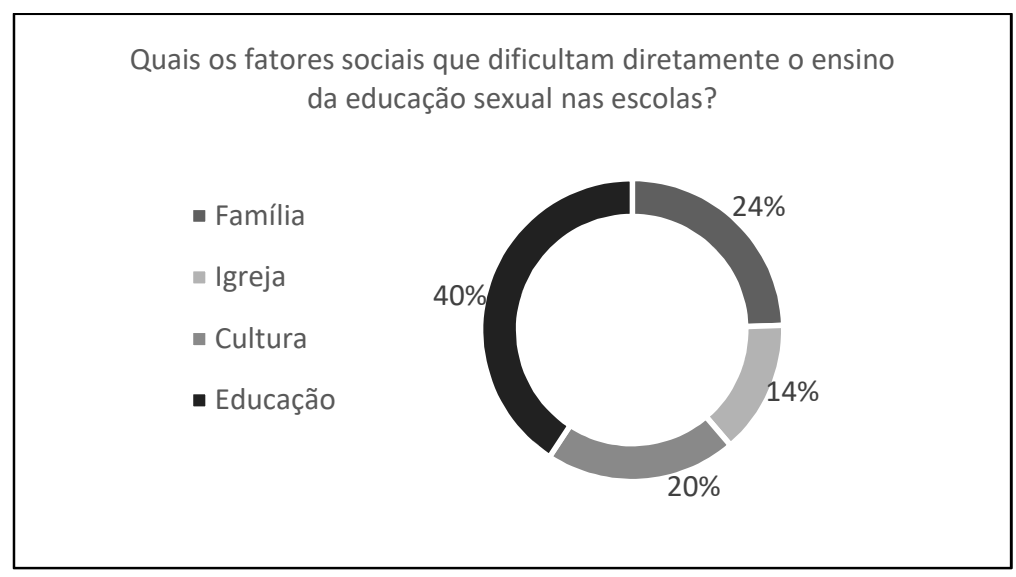

Figura 8: Fatores sociais que dificultam diretamente no ensino da educação sexual.

Educar sexualmente previne danos futuros, trabalhando o preconceito e o medo, trazendo informações seguras (LIMA et al., 2010). De acordo com Souza (1991), educar sexualmente consiste em oferecer condições para que as pessoas assumam seu corpo e sua sexualidade com atitudes positivas, livres de medo, preconceitos, culpas, vergonha, bloqueios ou tabus. Os pais possuem o papel de orientar seus filhos, e não dificultam a escola de se trabalhar o assunto. De acordo com os resultados, $90 \%$ dos entrevistados relataram que é papel dos pais realizar educação sexual e a escola atuar como parceira complementar, abordando os diversos assuntos dentro da temática, embora ainda não seja a realidade vivida pelos professores o que dificulta o processo de ensino. A educação sexual tem que ser compreendida como um direito das crianças e adolescentes, para que se tenha entendimento positivo de sua sexualidade e corpo, tendo pensamento crítico (ECOS, 2013). Além disso, oferece condições para que possa assumir seu próprio corpo sem medo, preconceito e vergonha (SOUZA, 1991).

\section{CONCLUSÕES}

O presente estudo possibilitou analisar o ponto de vista dos alunos a respeito do tema educação sexual e de como ele é abordado nas escolas de rede pública do município de Guaraí/To. Neste sentido, o trabalho permitiu verificar quais são os temas discutidos neste contexto, as influências externas, a importância de ser trabalhado dentro do ambiente escolar, entre outros fatores que podem ser de grande importância relacionado a este tema

De modo geral, pode-se observar a falta de capacitação dos professores que ministram a disciplina, a falta de material didático, a aversão em falar os assuntos relacionados a sexualidade, entre outros fatores. Para que se possa solucionar esse contexto, deve-se abordar a educação sexual de forma contínua e não em momentos episódicos como se é trabalhado. Existe a fundamental importância de se trabalhar aulas mais dinâmicas, que sai do tradicionalismo para que tenha mais relevância essa temática. É indispensável a quebra dos tabus existentes no ambiente escolar para formarem cidadãos sem preconceitos e para que vivam de forma harmoniosa na sociedade. 
Esta pesquisa contribuiu para solucionar os desafios presentes de se lidar com o assunto no ambiente escolar, e analisar as influências sociais e por parte da família do aluno, propondo novas metodologias de ensino. $\mathrm{O}$ trabalho mostrou a importância dos pais no processo de aprendizagem dos seus filhos, colaborando de tal maneira para que possa ser significativa e incentivadora no ensino sexual.

\section{REFERÊNCIAS}

ALTMAN, H.. Orientação sexual nos Parâmetros Curriculares Nacionais. Revista de Estudos Feministas, v.9, n.2, 2001.

BELMONT, R.; LEMOS, E. A.. Aprendizagem Significativa nos trabalhos apresentados no 1 은 Encontro Nacional de Aprendizagem Significativa: reflexões iniciais. In: ENCONTRO NACIONAL DA APRENDIZAGEM SIGNIFICATIVA-ENAS, 2. Anais. Canela, 2008.

BERALDO, F. N. M.. Sexualidade e escola: espaço de intervenção. Psicologia escolar e educacional, v.7, n.1, 2003.

BOMFIM, S. S.. Orientação sexual na escola: tabus e preconceitos, um desafio para a gestão. Monografia (Graduação em Pedagogia) - Universidade do Estado da Bahia, Salvador, 2009.

BRASIL. Parâmetros Curriculares Nacionais: pluralidade cultural, orientação sexual. 3 ed. Brasília, 2001.

BUENO, S. M. V.; MOIZÉS, J. S.. Compreensão sobre sexualidade e sexo nas escolas segundo professores do ensino fundamental. Revista da Escola de Enfermagem da USP, v.44, n.1, 2010.

CANO, M. A. T.; SALOMÃO, R.; SILVA, M. A. I.. Sexualidade do adolescente na percepção dos pais, sob a perspectiva de Foucault. Revista Eletrônica de Enfermagem, v.15, n.3, 2013.

DINIZ, D.; LIONÇO, T.. Homofobia, silêncio e naturalização: por uma narrativa da diversidade sexual. Revista Psicologia Política, v.8, n.16, 2008.

FERNANDES, R. C. A.; XAVIER, O.S.. A Aula em Espaços Não-Convencionais. In: VEIGA, I. P. A. Aula: Gêneses, Dimensões, Princípios e Práticas. Campinas: Papirus, 2008.

FIGUEIREDO, A. C.. Condições de vida e saúde reprodutiva de adolescentes na comunidade Roda de fogo. Revista Brasileira Materno Infantil, Recife, v.2, n.3, 2002.

GOMES, R. S.. Educação em sexualidade na escola: entre a normalização e a perspectiva dos direitos humanos. Seminário Internacional Fazendo Gênero, v.10, 2013.

LARROSA, J.. Tecnologias do eu e educação. In: SILVA, T. T.. O sujeito da educação: estudos foucaultianos. 2 ed. Petrópolis: Vozes, 1994.

LIMA, A. A.; OLIVEIRA, D. C.; PEREIRA, J. A.; SOUZA, E. S.. Educação sexual infantil: interação entre a família e a escola como um fator determinante para uma educação eficaz. Pedagogia em Ação, v.2, n.1, 2010.

LOURO, G.. Pedagogias da sexualidade. In: LOURO, G.. O corpo educado: pedagogias da sexualidade. Belo Horizonte: Autêntica, 1999.

PAULA, M. C.. TAQUETTE, S.R.; VILHENA, M. M.. Doenças sexualmente transmissíveis e gênero: um estudo transversal com adolescentes no Rio de Janeiro. Saúde Pública, Rio de Janeiro, 2004.

QUIRINO, G. S.; ROCHA, J. B. T.. Sexualidade e educação sexual na percepção docente. Educar em Revista, Curitiba, n.43, 2012.

REIS, E. A.; REIS, I. A.. Análise Descritiva de DadosTabelas e Gráficos: Relatório Técnico RTE04/2001. Belo Horizonte: ICEx/UFMG, 2001.

SAMPAIO, S.. Educação sexual: para além dos tabus. Revista ABC Educatio, 2005.

SILVA, B. O.; RIBEIRO, P. R. C.. Sexualidade na Sala de Aula: Tecendo Aprendizagens a partir de um Artefato Pedagógico. Florianópolis: 2011.

SOUZA, H. P.. Convivendo com seu sexo: pais e Professores. 2 ed. São Paulo: Paulinas, 1991. 